\title{
A Fast Way to Estimate the Minimum Principal Stress (S3) in the Cap Rock Applied to Development of Brazilian Pre-Salt Petroleum Fields using Seismic Data
}

Talles Barsanti Meneguim ${ }^{12}$, Antonio M. Nabuco Tartarini' ${ }^{1}$, Ligely Dias Quitar Vieira' ${ }^{1}$, Alexandre Rodrigo Maul1", Raquel Quadros Velloso', ${ }^{1}$ Petrobras S.A., ${ }^{2}$ PUC-RJ

Copyright 2021, SBGf - Sociedade Brasileira de Geofísica.

This paper was prepared for presentation during the $17^{\text {th }}$ International Congress of the Brazilian Geophysical Society held in Rio de Janeiro, Brazil, $16-19$ August 2021.

Contents of this paper were reviewed by the Technical Committee of the $17^{\text {th }}$ International Congress of the Brazilian Geophysical Society and do not necessarily represent any position of the SBGf, its officers or members. Electronic reproduction or storage of any part of this paper for commercial purposes without the written consent of the Brazilian Geophysical Society is prohibited.

\begin{abstract}
The carbonate reservoirs of the Brazilian Pre-Salt, especially in the Santos Basin, are deep reservoirs surrounding TVDSS of more than $5000 \mathrm{~m}$, located in ultra-deep-water column in average over than $2000 \mathrm{~m}$. Santos Basin offshore has a complex stratigraphic column above the carbonate reservoirs composed by a mixing salt section, albian carbonatic rafts and siliciclastic sediments. In general terms considering the geotechnical effects the salt section acts as the seal for the pre-salt reservoirs. That seal is mainly composed by halite and the base of the salt section is marked for anhydrite presence as confirmed by almost 300 drilled wells. Halite and others mobile salts such as carnallite and tachyhydrite exhibits more ductile behavior rather than the fragile behavior observed in anhydrite and less susceptibility to failure by thermic effect during cold-water injection. All these features added the fact the salt section is composed around $80 \%$ of halite, make the estimation of minimum principal stress (S3) at cap rock halite a critical task to define the maximum injection pressure at reservoir and so keep the profits and oil production as well as the security in the field development. To model all these 3D complexities in the Brazilian Pre-Salt Santos Basin a longer time is necessary, besides an integrated cooperated work involving many disciplines as: geophysics, geology, reservoir and well engineering. One of the most relevant quantity for petroleum field's development is the minimum principal stress (S3) at cap rock into the wells to define the best production strategy. The injected volume at reservoir must keep the field's oil volume production and profits at same time it guarantees of the security in regarding the seal rock integrity. Doubtless, a complex 3D geomechanical model is the best attempt to estimate S3 even involving much longer time spent. At this work is showed a simple method to estimate it using a probabilistic approach through seismic structural maps and their statistic distribution. A such estimative is done using 1000 realizations to infer the major principal stress (S1) in the hydrostatic cap rock halite, in a stochastic 1D simulation manner and gives the probabilistic estimative: P50(base), P10 (pessimistic) and P90(optimistic) for the minimum principal stress (S3) at cap rock in a fast way. We emphasized the greater robustness of a built complex 3D geomechanical modeling. We show another case covering the seismic and geomechanical integration that allows a fast analysis of the reservoir team dealing with risks mitigation associated to the seal integrity in the absence of more reliable and complex 3D estimations.
\end{abstract}

